\title{
The Anthropometric Study of the Portuguese Population Using 3D Body Scanning Technology - Its Contribution to the Improvement of Size Tables
}

\author{
Ana Florinda RAMÔA ${ }^{1}$, Ana BARROS ${ }^{1}$, José MORGADO ${ }^{1}$, Ana Paula DINIS ${ }^{2}$ \\ ${ }^{1}$ CITEVE - Centro Tecnológico das Industrias Têxtil e do Vestuário de Portugal, \\ Vila Nova de Famalicão, Portugal; \\ ${ }^{2}$ ATP - Associação Têxtil e Vestuário de Portugal, Vila Nova de Famalicão, Portugal \\ DOI: 10.15221/18.297 http://dx.doi.org/10.15221/18.297
}

\begin{abstract}
This paper presents the methodology used in the anthropometric survey of the Portuguese population. There is a lack of information in the construction of size tables and this could pose a big problem for brands mainly due to a significant increase in online shopping. Clothes should be comfortable and have a good fit. Size tables not adjustable to end users can represent a high return rate, making stock management very difficult. In Portugal there are some anthropometric studies conducted essentially by Universities and medical centres for civilian and military use. However these studies are made only for very restrictive groups of the population and do not provide the information that garment companies need to construct size tables. On the other hand, there is very few information at an European level.
\end{abstract}

There is an European standard, the EN13402 [1,2,3], but when a garment company tries to use its information to build their size tables, they are faced with a lot of difficulties, mainly:

- The size tables used by industrial companies have more measurement points than the Standard;

- The EN13402-3 [3] standard has some examples that are supposed to help companies in the construction of their size tables, however, the combinations of values are numerous, and if garment companies do not have any anthropometric data about their target population it is virtually impossible to construct an adequate size table relying only on the EN13402-3 [3] Standard.

In order to help companies acquire the necessary information to construct their size tables, CITEVE and ATP did an anthropometric study on the Portuguese population, which was carried out on different parts of the country, with the inclusion of both men and women between the ages of 18 and 86 years old. The study was conducted using the TC2 body scanner, measuring 119 different points (waist, hip and bust girths as example).

The main results of the survey are:

- The basic statistics for the 119 measurement points (mean, standard deviation, ...);

- The measurements identification of the "average Portuguese", male and female;

- The evolution of the measurement points (bust/chest, hip, waist), by age groups, which is important for the grading system;

- A tool to help companies to analyse if their size tables are adjusted to the Portuguese population and to better manage their stocks inside the shops.

Keywords: Antropometry, 3d body scanning, size table

\section{Introduction}

The construction of size tables is a crucial step for garments companies, as their sales strongly depend on the adequate fit of the garments when sold to the end-users. The continuous relocation of production units, the use of sewing patterns based on body dimensions not updated, as well as limited information regarding standardization of sizing designation systems, has resulted in numeral complaints from consumers. In a study conducted in 2011, by CITEVE, $40 \%$ of Portuguese women said that have had problems in judging their sizes. These issues can pose several problems for garments companies, especially in the development of online sales, resulting in an increased number in returns and in a high number of garments left over after each season.

Regarding standardization, there is an European Standard (EN 13402 - Size designation of clothes), which aims to label clothes' sizes. However, when garments companies try to use information from this standard to construct their size tables, they encounter several problems: (i) the size tables used by industrial companies have way more measurement points than those described in the standard; (ii) although the standard allows for multiple combinations to help companies in the construction of size tables, it is necessary for companies to have anthropometric data about their target population (otherwise, it is virtually impossible to construct them based exclusively on this standard). 
Taking into account the main problems associated with the lack of information regarding sizing and size tables, administrations and business groups from the textile industry have incentivise the development of anthropometric studies in several countries. However, these studies have been performed internally by each country, using different measuring methodologies, which makes the comparison and standardization of data more difficult at an international level.

France, Spain (for women), United Kingdom, United States of America, Australia and others are examples of countries which have already carried out anthropometric studies for these purposes. In Portugal, a few studies have been conducted, but only on small groups: some studies have been performed at an University level and other studies have involved medical centres and the Portuguese Army. Nevertheless, these studies are not representative of the overall population and the obtained results are not available for companies.

To supply companies with the adequate and necessary information for the construction of size tables, CITEVE and ATP have conducted an anthropometric study of the Portuguese population, which was carried out in different parts of the country and has included both men and women. The study has been made under an European Project called "Transregional network for technology transfer and innovation in the sector of fashion and confection of the SUDOE region through the exploitation of anthropometric databases of the population" whose acronym is SIZING SUDOE, between September 2011 and March 2015.

\section{Methodology}

\subsection{Body measurements procedure}

The anthropometric measurement of the Portuguese population was made with a Body Scanner (3D Scanning Technology) equipped with infrared sensors (IR Depth Sensor), the KX-16 3D Body Scanner from (TC) 2, which according to the manufacturer is not harmful [6]. Fig. 1 represents the Body scanner used in this study.

The volunteers are anonymous, (it is not possible to identify whom the data belongs to) and confidential (the individual data are not intended to be delivered to third parties) - the data is only to be used to calculate descriptive statistics like mean, standard deviation, minimum, maximum, and other statistics. Each participant had to fill a Declaration of Consent - a document allowing the collection of personal data (body measurements). Before the Anthropometric study, it was also necessary to acquire an authorization from the Portuguese Data Protection Authority.

Beyond the measurements given by the Body Scanner, a questionnaire (Sociodemographic Questionnaire) was also filled out to complement the information acquired by the Body Scanner (body measurements). Data collected in this questionnaire included age, district of residence (Portugal has $18)$, among others. The weight was also measured with a scale.

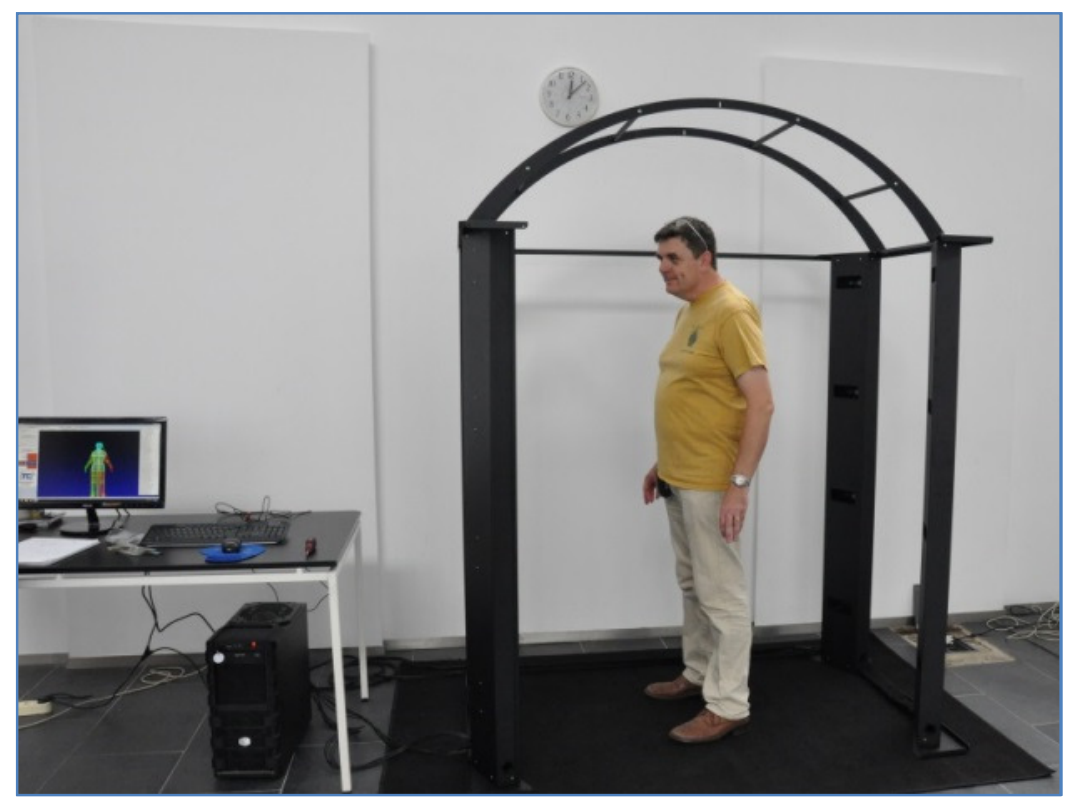

Fig. 1: CITEVE Body Scanner 


\section{Procedure}

- Each participant was guided to the dressing room area where they had to undress (remaining in underwear) and be barefoot.

- Participants with long hair had to put a cap (swimming type) to catch the hair.

- When in underwear, the person moved to the measuring area of the body scanner and followed the instructions of the CITEVE technician about the posture to adopt.

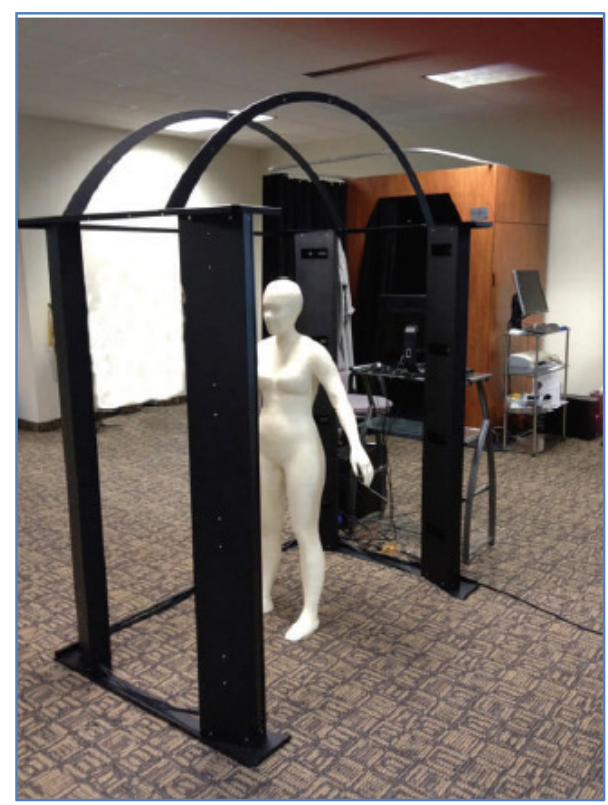

Fig.2: Position to measurement

- The participation was anonymous. It is never possible to identify the person whom the measurements belong to. In response, each participant was given a code (female gender: F0001, F002, ... and male gender: M0001, M002, ...), which was not connected to the individual's information, protecting his/her identity;

- The CITEVE technician, after evaluating the data, asked the participant to return to the dressing room area;

- The Results Sheet (3D image and measurements obtained) was printed and delivered to each participant (Fig. 3).
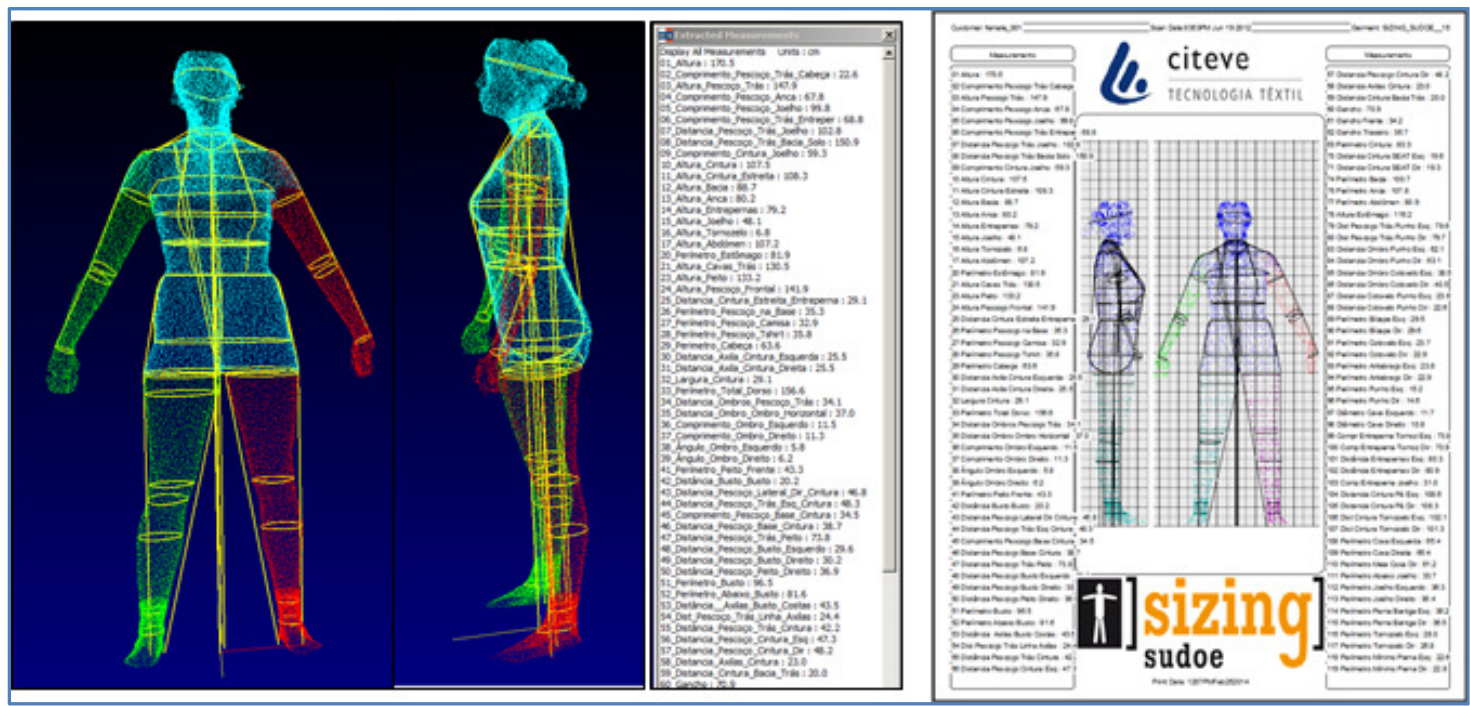

Fig.3: Information delivered to each participant (Results Sheet).

After acquiring the body measurements with the Body Scanner, each person was asked to fill the Sociodemographic Questionnaire and measure his/her weight on a scale. 


\subsection{Data Collected}

The Body scanner allows for an automatic body measure, with over 400 "measurement points" [6]. For the anthropometric study of the Portuguese population, 119 have been selected.

A total of 1189 women between the ages of 18 and 83 years and 806 men, from 18 to 86 years old, all originating from the 18 districts of mainland Portugal have participated. The measure were carried out in 4 geographical regions (Vila Nova de Famalicão, Póvoa de Varzim, Portimão and Vila Nova de Gaia).

After data cleaning, which aimed to detect, remove anomalies and to increase and improve its quality, the decision was made to use the statistical analysis from 1094 women and 769 men.

For the anthropometric study, the scanned sample has been distributed in 4 groups. The representativeness of the scanned sample versus mainland Portuguese population [7], by age group, can be analysed in Table 1.

\begin{tabular}{|c|c|c|c|c|}
\hline \multirow{2}{*}{ Age group } & \multicolumn{2}{|c|}{ Women } & \multicolumn{2}{c|}{ Men } \\
\cline { 2 - 5 } & $\begin{array}{c}\text { Portuguese } \\
\text { Population }\end{array}$ & Scanned sample & $\begin{array}{c}\text { Portuguese } \\
\text { Population }\end{array}$ & Scanned sample \\
\hline $18-34$ & $25 \%$ & $32 \%$ & $27 \%$ & $30 \%$ \\
\hline $35-54$ & $35 \%$ & $34 \%$ & $37 \%$ & $36 \%$ \\
\hline $55-75$ & $29 \%$ & $33 \%$ & $28 \%$ & $33 \%$ \\
\hline$>76$ & $12 \%$ & $1 \%$ & $8 \%$ & $2 \%$ \\
\hline
\end{tabular}

Table 1: Age distribution of scanned persons $x$ Portuguese population

\subsection{Data analysis}

The final result of the study is a database (Fig. 4) containing the Sociodemographic Questionnaire and the values of the 119 measurement points, from both sides of the person's body except head, hands and feet, of 1863 people.

\begin{tabular}{|c|c|c|c|c|c|c|c|c|}
\hline Peso (kg): & Idade & Nacionalidade & Distrito & $\begin{array}{l}\text { Código de } \\
\text { utilizador }\end{array}$ & Name & 01_Altura & $\begin{array}{l}\text { 02_Comprimento_P } \\
\text { escoşo_Trás_Cabeça }\end{array}$ & $\begin{array}{c}\text { 03_Altura_Pescoşo } \\
\text { Trás }\end{array}$ \\
\hline 46.2 & 65 & Portuguesa & Porto & Foo1 & Foo1 & 147.65 & 22.14 & 125.51 \\
\hline 62 & 19 & Portuguesa & Braga & Fo03 & F003_2 & 168.09 & 22.58 & 145.52 \\
\hline 47 & 56 & Portuguesa & Porto & F004 & F004_2 & 156.23 & 23.46 & 132.76 \\
\hline 84 & 63 & Portuguesa & Braga & Foos & Foos_3 & 162.72 & 21.57 & 141.15 \\
\hline 75 & 56 & Portuguesa & Porto & Foo6 & F006_2 & 166.65 & 26.68 & 139.97 \\
\hline 61 & 46 & Portuguesa & Braga & F008 & F008_3 & 158.42 & 23.69 & 134.73 \\
\hline 52 & 51 & Portuguesa & Porto & Foo9 & Foo9_2 & 153.23 & 22.38 & 130.86 \\
\hline 68 & 55 & Portuguesa & Braga & Fo10 & Fo10 & 163.18 & 23.13 & 140.05 \\
\hline 70 & 24 & Portuguesa & Aveiro & Fo11 & Fo11 & 163.17 & 24.20 & 138.97 \\
\hline 53 & 67 & Portuguesa & Porto & F012 & F012 & 160.58 & 23.05 & 137.53 \\
\hline 59 & 61 & Venezuela & Braga & F013 & F013 & 154.65 & 21.59 & 133.06 \\
\hline 57 & 57 & Portuguesa & Braga & F014 & F014 & 156.43 & 21.21 & 135.23 \\
\hline 60 & 44 & Portuguesa & Porto & F015 & F015_2 & 158.77 & 23.27 & 135.51 \\
\hline \multicolumn{5}{|c|}{ Sociodemographic questionnaire } & \multicolumn{4}{|c|}{ Body scanner } \\
\hline
\end{tabular}

Fig.4: Example of the final database

\section{Results and Discussion}

This section presents some results of the statistical analysis made for public dissemination. The data shown are the average values of some measured points like bust/chest, waist and hip. 


\subsection{Corporal Morphology by Age Group}

\section{- Height by age group (cm)}

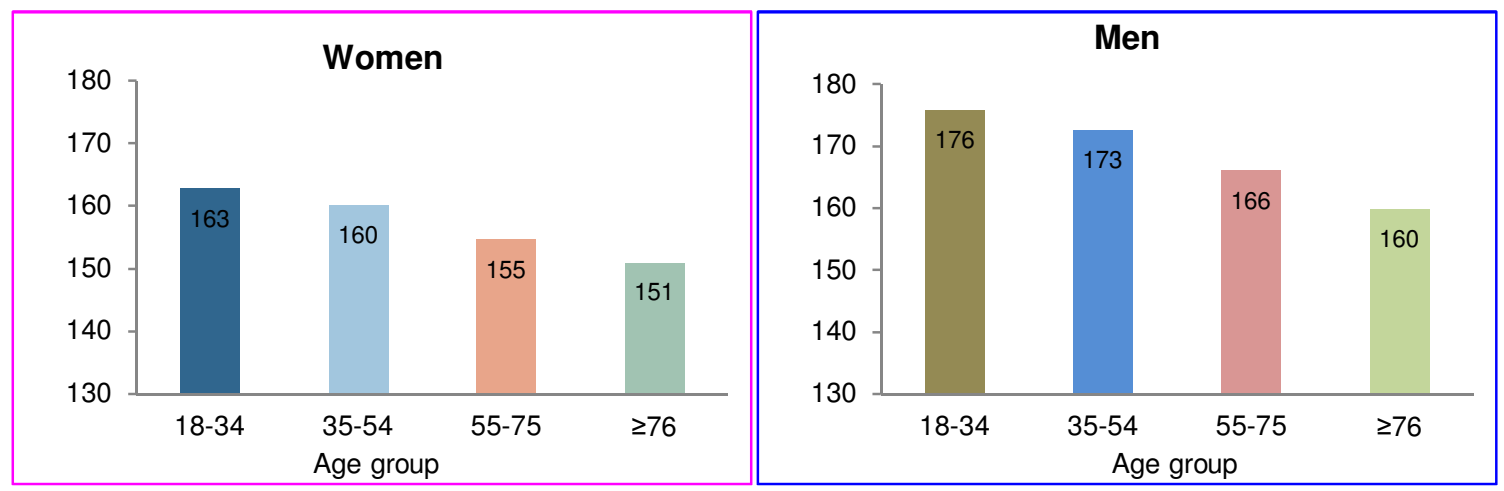

Fig. 5: Women and men height by age group

As Fig. 5 shows, younger people are higher than older people. This means that the size tables should be adapted to each target public.

\section{- Bust/Chest girth (cm)}
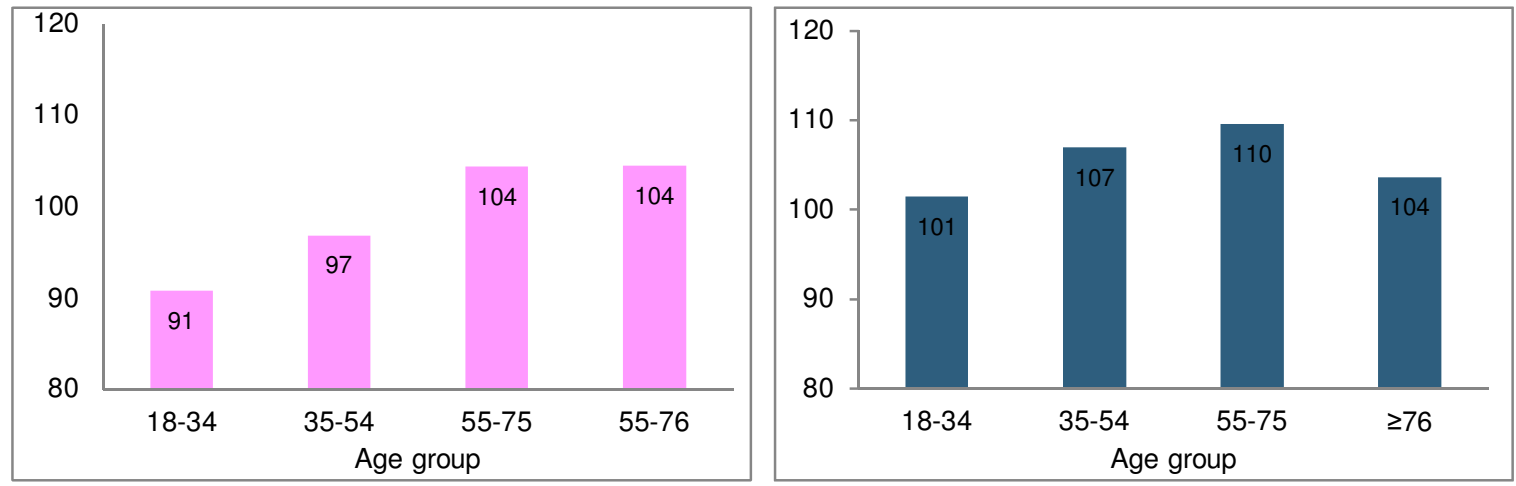

Fig. 6: Women and men bust/chest by age group

As Fig. 6 shows the women bust increases with the age. The difference between the ages of 18-34 to $55-75$ is of $+13 \mathrm{~cm}$ and remains constant from 55-75 to the oldest group. For men, the increase it is not so higher, is of $9 \mathrm{~cm}$ from the ages 18-34 to 55-75 and have a decrease of $6 \mathrm{~cm}$ from 55-75 to the oldest group.

\section{- Waist girth (cm)}
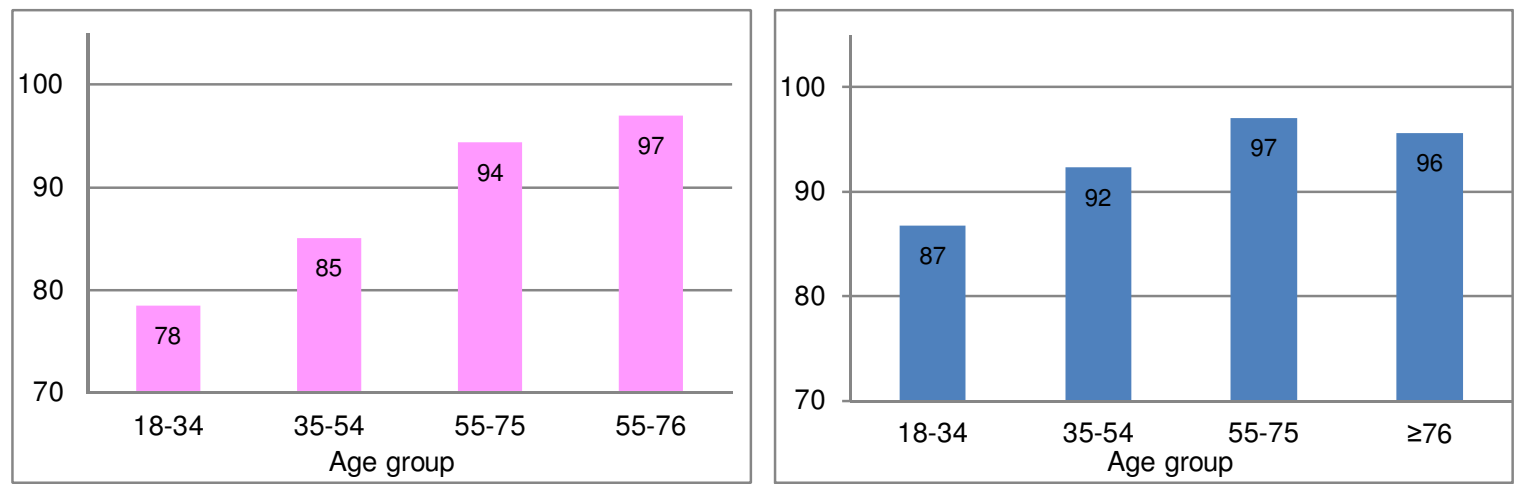

Fig. 7: Women and men waist by age range

As Fig. 7 shows, for women the difference between the youngest group and the oldest one is expressive $(+19 \mathrm{~cm})$. For men the difference between the ages $18-34$ to $55-75$ is of $+10 \mathrm{~cm}$ and have a decrease of $1 \mathrm{~cm}$ from 55-75 to the oldest group. 
- Hip girth (cm)

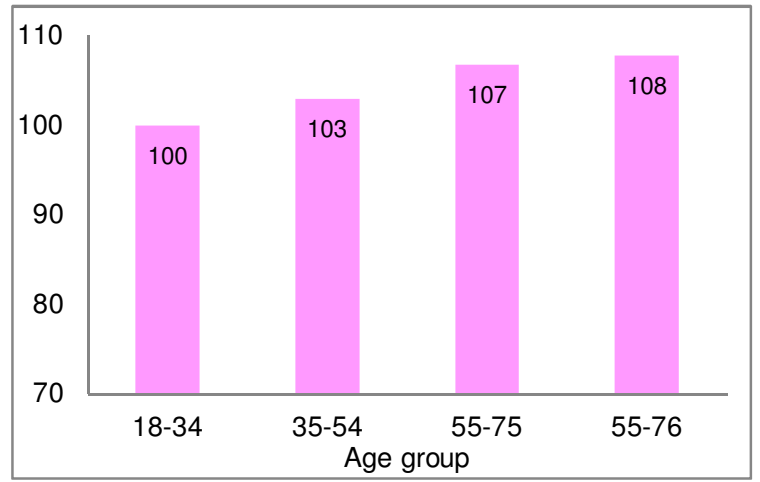

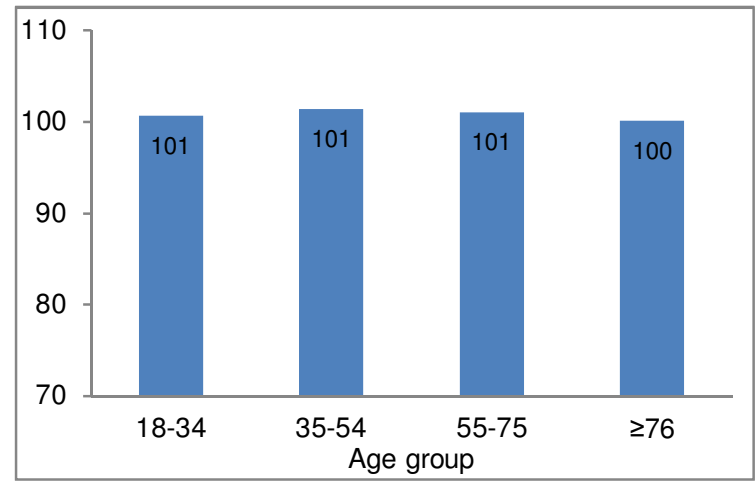

Fig. 8: Women and men hip by age range

As Fig 8 shows, the difference between the youngest group and the oldest one is of $+8 \mathrm{~cm}$ for women and $-1 \mathrm{~cm}$ for men.

With this analysis it is possible to conclude the anthropometric data of a population is of extreme importance for the construction of size tables. With this information brands (and clothing companies) knowing their target groups can define the values of each point (waist, chest and hip, ..., girth) and can create a grading system accomplished with the body differences - the increase on hip and waist probably should not have the same value if they don't increase with the same values.

\subsection{Representativeness of the Portuguese population on the intervals of the EN 13402-3}

Presented here, is the representability (in percentage) of the Portuguese population in the intervals considered on two Tables of the European standard 13402-3:2013 ${ }^{1}$, one for men (Table 2) and other for women (Table 3).

The publication of Standard EN 13402: "Size designation of clothes" intended to clarify questions related with the sizes of clothes in order to help companies and consumers, adjusting the size designation of clothes on the body's dimensions and not on the clothes' dimensions. On clothes construction, the adequate tolerances should be considered.

The standard is divided in four parts. In this study, only Part1 - Part 3 were used. Part 1, defines the body dimensions for garments, specifies the procedure for measuring the body and provides pictograms to use on clothing labels. Part 2 , specifies the primary and secondary dimensions for different types of garments. Part 3, presents size tables for different measurement points (bust, waist, ... girth) and defines intervals for the construction of size tables.

Based on Part 3 of the Standard, the representativeness of the Portuguese population on the intervals of some tables of the standard has been calculated. Below it is possible to analyse two examples of those.

- Rows in blue, are not present at the standard, they have been added to the Table.

- The intensity of the green colour grows with the increase of the percentage of people existing in each interval.

Its objective is to help companies in the construction, or improvement of their size tables.

For this article (based on project Sizing Sudoe) has been used the EN 13402-3:2013 "Size designation of clothes" - Part 3: Size labelling based on body measurements and intervals" but this kind of analysis is possible to make to any size table.

\footnotetext{
1 The analysis have been made based on EN 13402-3 October 2013, since the anthropometric study of the Portuguese population has been made under an European Project called "Sizing Sudoe" between September 2011 and march 2015, however, there is an EN 13402-3 September 2017. In this new version the ranges for the tables are slightly different.
} 


\section{- Men: Upper Body Clothing (chest and waist girth)}

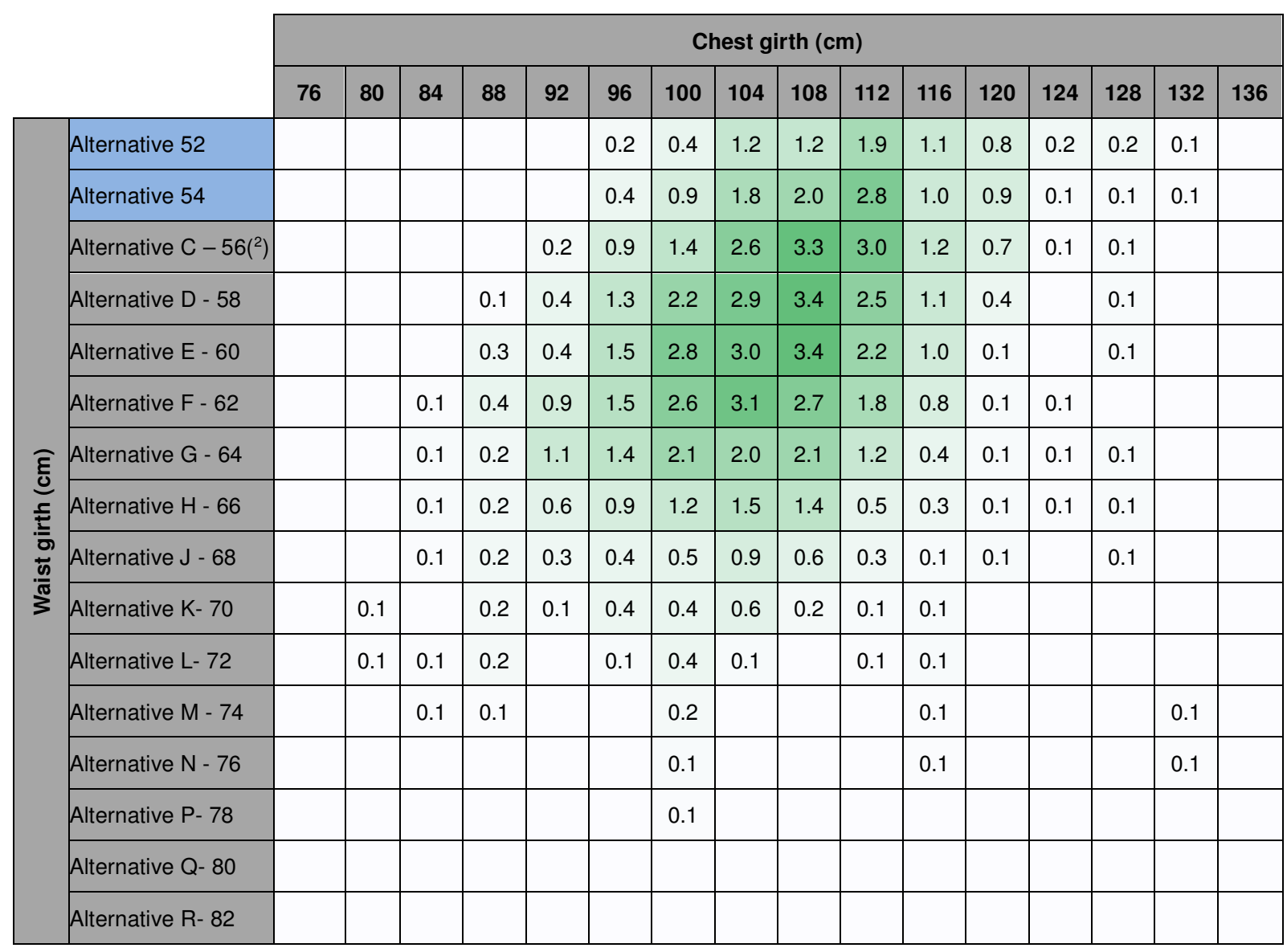

Table 2: - Frequencies according to table 4 of the EN 13402-3:2013 standard (values in percentage)

At Table 2 it is possible to see that the Portuguese men have a smaller waist girth than it is considered in the standard. Even with the addition of two alternatives it is possible no see that smaller sizes could be consider.

\footnotetext{
${ }^{2}$ Alternative C-56: 56 corresponds to the inferior limit of the range (ex: 56-60)
} 


\section{- Women: Garments for lower body (waist and hip girth)}

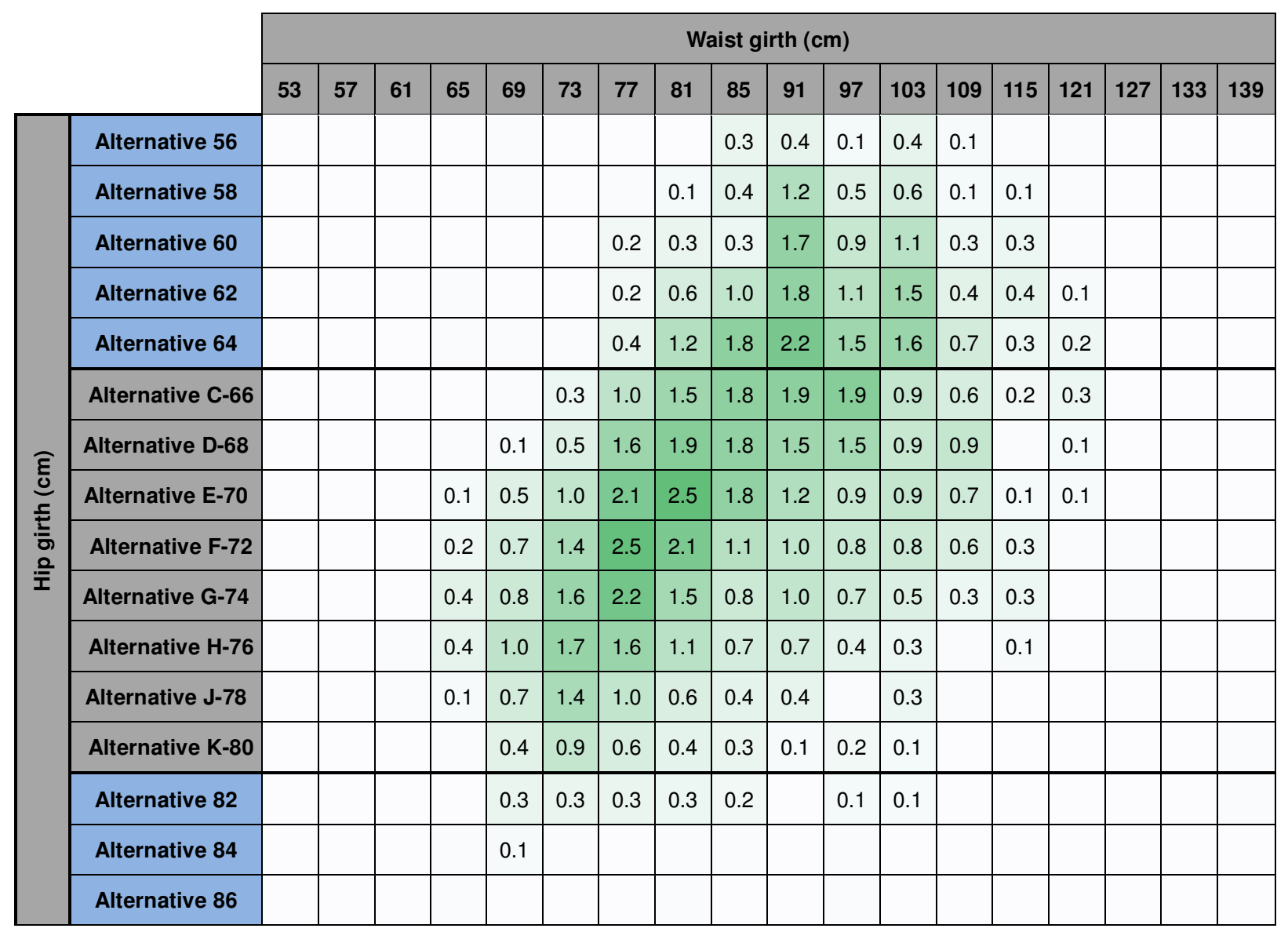

Table 3 - Frequencies according to table 17 of the EN 13402-3:2013 standard (values in percentage)

At Table 3 it is possible to see that the Portuguese women have a smaller hip girth than it is considered in the standard and also larger. In this table have been added more alternatives, smaller and bigger sizes could be consider.

\subsection{Construction of size tables adapted to Portuguese population}

With the kind of analysis explicated at the points 3.1. and 3.2. it is possible to construct size tables which allows the production of clothes that better fits the Portuguese population.

Briefly it is possible to say that to construct the size table with the other measurement points, it is necessary to identify the principal component [3], that it is the measurement used as the basis for the development of the size table (some companies use the secondary dimension as referred at the EN 13402-2: 2006 standard). After, it is necessary to do a regression analysis to analyse how well the other measurement points are related ${ }^{3}$, to decide the limits (smallest and biggest sizes) - based in the analysis made for the construction of Table 2 and Table 3 , and to predict the values of the other measurement points using regression equations.

${ }^{3} \mathrm{R}^{2}$ is a statistical measure of how close the data are to the fitted regression line. 


\section{Conclusions}

This anthropometric study has taken into account 119 measurement points. For each of these points, the basic statistics (mean, standard deviation) have been determined. The evolution of the measurement points (bust/chest, hip and waist) with the age was also analysed in this study, since it is an important factor for the grading system. Additionally, considering two examples of Tables of the EN 13402-3:2013 "Size designation of clothes", has been calculated the representability of the Portuguese population. This kind of analysis allows the determination of the smallest and biggest sizes of the size tables, the number of sizes and values of the ranges and also to adjust production quantities for each sizes (stock management).

In summary, the results presented in this study constitute an important tool to help companies to (i) assess if their size tables are adjusted to the Portuguese population; (ii) reconstruct their size tables (mainly to adjust their grading system) while taking into account the measures of the Portuguese population and the target market (in terms of gender, age and others); (iii) better manage their stocks inside the shops.

\section{References}

[1] EN 13402-1:2003 "Size designation of clothes - Part 1: Terms, definitions and body measurement procedure".

[2] EN 13402-2: 2006 "Size designation of clothes - Part 2: Primary and secondary dimensions".

[3] EN 13402-3:2013 "Size designation of clothes" - Part 3: Size labelling based on body measurements and intervals.

[4] Ana Florinda Ramôa, et al, "Estudo Antropométrico da População Portuguesa", CITEVE, ATP, Vila Nova de Famalicão, Portugal, 2015.

[5] Elizabeth Anne Newcomb, "Body Shape Analysis of Hispanic Women in the United States", thesis submitted to the Graduate Faculty of North Carolina State University in partial fulfillment of the requirements for the Degree of Master of Science, 2005.

[6] David BRUNER, "KX-16: 3D Body Scanning Using Low Cost Depth Sensors", [TC]2, Textile/Clothing Technology Corp., Cary (NC), USA, paper presented at the Asian Workshop on 3D Body Scanning Technologies, Tokyo, Japan, 17-18 April 2012.

[7] Census - Final results. Portugal - 2011, https://www.ine.pt/xportal/xmain?xpid=INE\&xpgid=ine publicacoes\&PUBLICACOESpub boui=7 3212469\&PUBLICACOESmodo=2\&xlang=en 